\title{
3. Doing Research on Subnational Levels of Autocracies: Field Work and Methodological Approach
}

\author{
Miriam Bohn, Thomas Demmelhuber, and Erik Vollmann
}

Field research in non-democratic contexts is challenging. Even prior to the Arab uprisings the clustering of autocratic regimes in the MENA region held great obstacles regarding access to the field, access to data and archives, and identification of potential interview partners or participants for survey research. In most cases, research played out within legal "grey zones" in terms of official permissions to conduct research. International scholars were granted access to the field via tourist visas and fieldwork was conducted with the implicit toleration of the security apparatus. Even so, there is a tacit knowledge among the research community regarding the unvoiced but clearly defined "red lines" that limit the scope and possibilities of research and movement in the field.

The Arab uprisings were more than a turning point for the social and political configuration of the region. The newly evolving political map impacts research on and in the region. The reasons for this are manifold, but three related aspects stand out: First, in times of popular upheavals narratives of alleged clandestine interventions by external actors lent cause to ruling regimes to identify actors from abroad purportedly responsible for instability and turmoil (also referred to as "the third hand", Wessel 2018). This led to a tremendous increase in suspicion toward foreign researchers, who are increasingly considered agents of external intelligence or other external parties. Second, the security apparatus in most MENA countries invested a lot in domestic surveillance techniques, both in offline and online, making it even more difficult to acquire the consent of potential interviewees. And third, in times of changing makeup of political power and not fully established top-down capacities, competing security/police branches may lead to diverging interpretations of what is allowed and lawful and what is not. Experiences of arbitrary arrests and misuse of power have been the consequence for many researchers in the MENA region. This fundamental change has led to a thriving literature in the field of how to do research in authoritarian contexts, which was long overdue (Glasius et al. 2018; Grimm et al. 2020). Based on these context factors, our research was driven by several methodological premises, benchmarks, and tools. 


\section{Case selection and period of investigation}

In this book we analyze the interplay of neopatrimonialism and decentralization in Morocco, Jordan, Tunisia and Egypt. To detect changes and continuities over time, we concentrate on the period from 1990 until 2020. As the most vital public discussions and reform endeavors regarding decentralization - as well as our fieldwork - took place after the Arab uprisings, the focus of our analysis is the period after 2011. The local governance discussions in the 1990s vastly reflected international donors' calls for subnational governance reforms and liberalization. We use the decentralization reforms of that era as a necessary baseline to assess the trajectories of change and continuity in the current generation of reforms. This broad timeframe enables us to capture major dynamics that show an impact on the development of decentralization in each country: continuing patterns as well as specific events. Despite a variance in regime type, size, urbanization and colonial history, our four cases experienced the Arab uprisings as heavily centralized authoritarian regimes with limited potential to pacify protests with classic instruments of a rent economy (e.g. increasing social welfare, subsidies). All four were considered neopatrimonial (see Table 1) at the time, and opted for a decentralization reform or enshrined it in their constitutions as a reaction to the protests. While major and regionally exceptional reforms followed in Jordan, Morocco and Tunisia, Egypt's propensity for reform has been curbed ever since the power transition to as-Sisi in 2014 (see Figure 1). 
Figure 1: Increase in local government power (V-Dem)

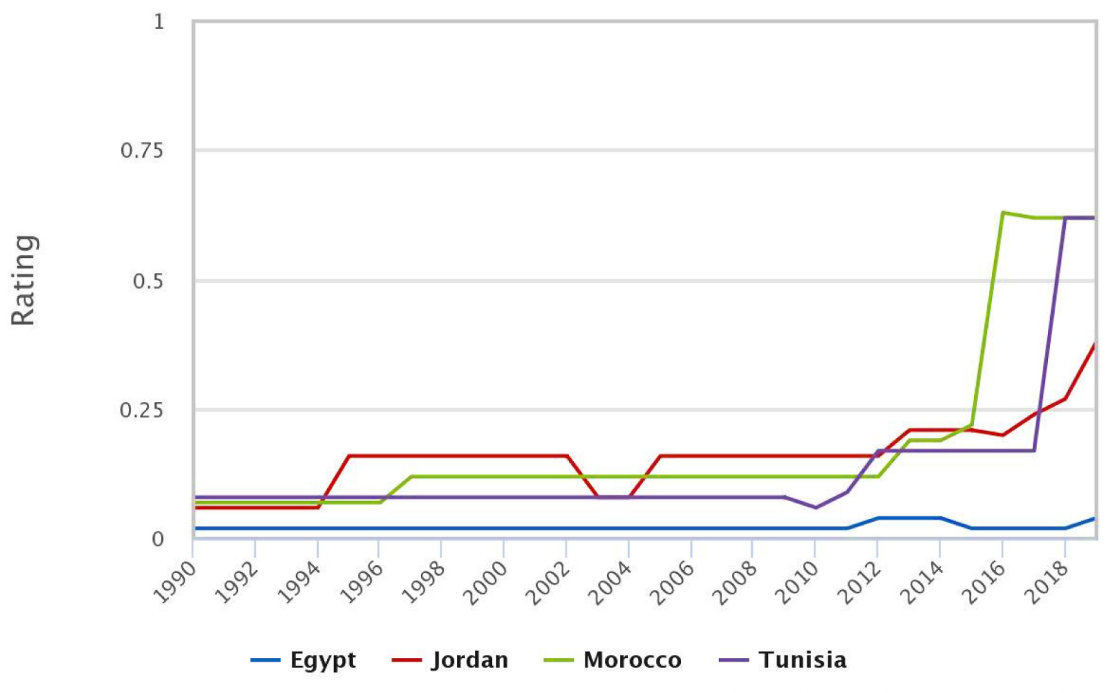

Highcharts.com | V-Dem data version 10.0

V-Dem (2020). Combined index of the existence of elected local governments and their power vis-à-vis nonelected actors on the same level, range between 0 (non-existent or subordinate) and 1 (existent and dominant).

Attempts to decentralize longstanding neopatrimonial structures unite these four countries. They are low- to middle-income MENA countries that cannot rely on rentierism alone to appease the protesters. Beyond these similarities, the four countries vary on important characteristics. In order to illustrate similarities and differences of the four cases under investigation, Table 1 summarizes major demographic and socio-economic features of each country. Egypt has the largest population, but also the lowest urbanization rate (despite a concentration of inhabitants in and around the Nile Valley). Jordan and Tunisia share a similar population size, but Jordan's degree of urbanization is significantly higher with a score of $91 \%$ of the population living in urban spaces. Jordan also encompasses by far the smallest territory in our sample. Central state power need not spread far from the capital Amman to reach the Jordanian hinterland, whereas Moroccan let alone Egyptian regime power is stretched thin over vast landscapes with dispersed populations. This might be an incentive to decentralize to increase the state's capacity in the periphery.

All our cases started as autocratic regimes. Morocco and Egypt both deteriorated from moderate to hardline autocracies between 2010 and 2020, 
while Jordan kept up its status as moderate autocracy. The most profound change occurred in Tunisia: The country developed from a hardline autocracy in 2010 to a defective democracy in 2020 in the aftermath of its political upheaval (see Table 1). Neopatrimonialism has been present in all countries for long periods of time. Comparing the V-Dem local government index of 2010 and 2019 (see Table 1), Egypt kept almost the same rating while Jordan and Morocco show slight decreases. Tunisia shows the biggest change with a score of 0.84 in 2010 and only 0.08 in 2019. This would suggest a full turnaround of neopatrimonial power structures. Ongoing corruption perception, the persistence of the old economic elites and the importance of favoritism cast doubt on that score. The corruption perception index remains relatively unchanged in the young democracy since 2012 and is on the same level as in the other political regimes. Moreover, survey data for the Global Corruption Barometer suggest that more Tunisians experienced increasing corruption in 2019 than the population of our other cases. This replicates the high popular skepticism of 2016, where Jordanians and Tunisians very clearly led our list of cases in terms of distrust. The percentage of people reporting they had to pay a bribe over the course of the previous year also remains relatively constant throughout the Tunisian transition. The level is significant, though it is lower than that reported for the other countries of the sample. The percentage of people who perceive government officials as corrupt are on a comparably high level in all four cases. Egyptian, Moroccan, and Tunisian local councils were (slightly) more often perceived as corrupt than their central governments in 2016. In 2019 (after the Tunisian decentralization reform), the young democracy drew equal to Jordan, where more people believe the government to be corrupt than members of local governments.

Table 1: Country characteristics in comparison

\begin{tabular}{|c|c|c|c|c|}
\hline & Egypt & Jordan & Morocco & Tunisia \\
\hline $\begin{array}{c}\text { Population (2019) in } \\
\text { million }\end{array}$ & 100.4 & 10.5 & 36.5 & 11.7 \\
\hline Area in km $\mathbf{~}^{2}$ & $1,001.450$ & 89.320 & $\begin{array}{l}446.550 / \\
710.850\end{array}$ & 163.610 \\
\hline $\begin{array}{c}\text { Urbanization in \% } \\
(\mathbf{2 0 1 9 )}\end{array}$ & 43 & 91 & 63 & 69 \\
\hline
\end{tabular}

1 Second value with disputed areas (primarily the Moroccan-controlled Western Sahara). 


\begin{tabular}{|c|c|c|c|c|}
\hline & Egypt & Jordan & Morocco & Tunisia \\
\hline $\begin{array}{l}\text { Percentage of } \\
\text { population in } \\
\text { capital }\end{array}$ & Cairo: 9.6 & Amman: 19.5 & Rabat: 5.2 & Tunis: 19.9 \\
\hline $\begin{array}{l}\text { Wealth group / GNI } \\
\text { per capita in USD } \\
(\mathbf{2 0 1 8})\end{array}$ & $\begin{array}{c}\text { Lower middle } \\
1800\end{array}$ & $\begin{array}{c}\text { Upper middle } \\
4210\end{array}$ & $\begin{array}{c}\text { Lower middle } \\
3090\end{array}$ & $\begin{array}{c}\text { Lower middle } \\
3500\end{array}$ \\
\hline \multirow{2}{*}{$\begin{array}{c}\text { System status, } \\
\text { current and before } \\
\text { uprisings (BTI } \\
\text { democracy score) }\end{array}$} & $\begin{array}{l}\text { 2020: hardline } \\
\text { autocracy }(3.5)\end{array}$ & $\begin{array}{l}\text { 2020: moderate } \\
\text { autocracy }(4.3)\end{array}$ & $\begin{array}{l}\text { 2020: hardline } \\
\text { autocracy }(3.7)\end{array}$ & $\begin{array}{l}\text { 2020: defective } \\
\text { democracy }(6.6)\end{array}$ \\
\hline & $\begin{array}{l}\text { 2010: moderate } \\
\text { autocracy }(4.2)\end{array}$ & $\begin{array}{l}\text { 2010: moderate } \\
\text { autocracy }(4.0)\end{array}$ & $\begin{array}{l}\text { 2010: moderate } \\
\text { autocracy }(4.1)\end{array}$ & $\begin{array}{l}\text { 2010: hardline } \\
\text { autocracy (3.8) }\end{array}$ \\
\hline \multirow{2}{*}{$\begin{array}{c}\text { Neopatrimonialism } \\
\text { (V-Dem index, 0-1, } \\
\text { low - high) }\end{array}$} & 2010: 0.68 & 2010: 0.51 & 2010: 0.41 & 2010: 0.84 \\
\hline & 2019: 0.67 & 2019: 0.36 & 2019: 0.3 & 2019: 0.08 \\
\hline \multirow{3}{*}{$\begin{array}{c}\text { Corruption } \\
\text { perception Index }\end{array}$} & 2019: 35 & 2019: 48 & 2019: 41 & 2019: 43 \\
\hline & 2015: 36 & 2015: 53 & $2015: 36$ & 2015: 38 \\
\hline & 2012: 32 & 2012: 48 & 2012: 37 & 2012: 41 \\
\hline \multirow{2}{*}{$\begin{array}{c}\text { Global Corruption } \\
\text { Barometer }^{3} \\
\text { Risen Corruption }\end{array}$} & 2019:/ & 2019: 55\% & 2019: 53\% & 2019: $67 \%$ \\
\hline & 2016: $28 \%$ & 2016: 75\% & 2016: $26 \%$ & 2016: 64\% \\
\hline \multirow[t]{3}{*}{ Paid bribe } & 2019: / & $\begin{array}{c}\text { 2019: 4\% / wasta: } \\
25 \%\end{array}$ & 2019: 31\% & 2019: 18\% \\
\hline & 2016: 50\% & 2016: 4\% & 2016: $48 \%$ & 2016: 9\% \\
\hline & 2013: 36\% & 2013: 37\% & 2013: 49\% & 2013: 18\% \\
\hline \multirow{2}{*}{$\begin{array}{l}\text { Government offi- } \\
\text { cials / Local govern- } \\
\text { ment councilors }\end{array}$} & 2019: / & 2019: 36\% / 28\% & 2019: 37\% / 38\% & 2019: 31\% / 27\% \\
\hline & $\begin{array}{c}2016: 27 \% / \\
36 \%\end{array}$ & 2016: 34\% / 24\% & 2016: 35\% / 39\% & 2016: 31\%/32\% \\
\hline
\end{tabular}

Own depiction based on data by BTI 2020; World Bank 2020; V-Dem 2020; OECD and UCLG 2019; Transparency International 2020a; b.

\section{Analyzing subnational dynamics under authoritarianism: Methodological approach}

The main argument of this book is that elite dynamics and interactions between all levels of governance - central, regional, and local - influence the process and the outcome of decentralization. Different strata of elites respond to the incentives of reforms and make use of or react to formal and informal practices and institutions that accompany such reforms, in order

2 From 0 (highest level of corruption) to 100 (clean).

3 Percentage of respondents. 
to maintain or gain more influence as well as to undermine the position of others. Eventually, elite behavior twists the logic of the decentralization process, leading to different outcomes from what was expected as a result of the de jure framework, for example in terms of elite representation within subnational institutions, or the efficiency and equality of public service distribution and economic development.

The analysis of elites is an important branch in current political science study. In order to widen our understanding of politics "beyond the center" (Hoffmann, Bouziane, and Harders 2013) it is necessary to extend the focus beyond the state as the main actor and the central level as unit of analysis. Including elite perspectives at different levels of politics is one way to accomplish this necessary shift in research. Conducting fieldwork interviews with elites can be a viable method to create original data that helps us to look beyond a static understanding of the state and the regime, and to reveal regime interactions with different strata of the populace. However, the research on elites is very heterogonous and up until now, literature does not provide a common understanding or definition of elites and how to approach them (Morris 2009; Mikecz 2012; Cochrane 1998; Rice 2010; Perthes 2004). For the purpose of this book, we employ a broad understanding of elites as a privileged group within society, characterized by proximity to power or with a particular expertise (Morris 2009, 209). Following the argument of Woods (1998, 2106ff.), elites have (1) privileged access to resources that may not only be material but also encompass coercion, organizational, administrative, or symbolic capital, as well as knowledge and psycho-personal elements (e.g. charisma). (2) Not every individual has particular access to all resources, but they are interlinked by networks of social or professional relations. Lastly, elites are (3) socially or discursively constructed as elite by the recognition of their elevated status visà-vis the population. Accordingly, this allows us to not only include the top-regime elites into our analysis but also to consider oppositional, professional, regional, local, or societal elites.

In the empirical chapters we employ a mixed method approach using established findings within the literature, official state sources, media reports, and original fieldwork. Our argument draws on fieldwork in Morocco (April 2018 - May 2018 and October 2018 - December 2018), Jordan (April 2018 - May 2018, October 2018 - November 2018 and January 2020 - February 2020), and Tunisia (October 2019 - November 2019 and January 2020 - February 2020), where we conducted semi-structured interviews $(n=162)$ with politicians and state employees, civil society actors, researchers, journalists, and foreign observer organizations on the central, regional, and local government levels. Because of the political situation in 
Egypt, the deteriorating academic freedom and major security issues, we decided not to conduct fieldwork in our fourth case study. Instead, we relied on an evaluation of existing literature, official state channels, media reports and country experts.

We employed clusters of open questions in three blocks relative to (1) the framework of decentralization and its implementation, (2) the financial organization of subnational governance, as well as (3) elite networks and the interactions between actors and institutions. Since the interviews were conducted in an authoritarian (or transitional) environment, the safety of our interview partners had priority. Though decentralization is not per se a "hot topic" in relation to security interests of authoritarian regimes, special care is important when dealing with state-elite relationships, discrepancies between the text of laws and their implementation as well as country-specific "red lines" (e.g. the decentralization process in Morocco is strongly connected to the king, the unsolved Western Sahara question, and even the protest movements in the northern Rif region). We thus decided not to specify the date of the interviews and the position of the interviewees (see Glasius et al. 2018 for an extensive discussion of obstacles and techniques during fieldwork in authoritarian environments).

\section{Fieldwork description}

Conducting fieldwork in the periphery of MENA countries is challenging. Every researcher aiming to analyze the subnational levels of government is confronted with a variety of vital questions: How can I get in touch with people far away from urban areas? How do I get there? Is it safe to stay overnight? How do I interact with local officials? How far can I go with my questions? In order to answer some of these questions and provide some insight into fieldwork on the subnational levels, we divided this section into two parts: the preparation phase and the actual field work.

\section{Preparation phase ahead of the field trip}

Planning potential interviews from abroad is difficult. It is possible to reach out to international organizations before the visit and to arrange meetings with them. However, local organizations or individual interviewees are hard to contact from abroad. Emails remain unanswered and establishing contact via mobile phone or instant messaging services is limi- 
ted to a small pool of pre-existing contacts. Even if this is the case, the contact person will usually ask the researcher to reach out to them as soon as they have arrived in the country to make an appointment. The focus of the preparation phase is thus the creation of a research plan, a questionnaire for interviews, and to collect sufficient information on safe research techniques in authoritarian contexts.

\section{Conducting fieldwork in the periphery}

Accordingly, the engagement phase of fieldwork usually starts upon arrival. The essential device for the researcher is a local SIM card as many interviewees rely exclusively on mobile phones for the coordination of appointments. The next step is thus to reach out to contacts via calls, instant messages and emails. The initial recruiting of interviewees is based on (1) suggestions of colleagues who were kind enough to share contact information and (2) on a pool of observer organizations (especially the German political foundations). The latter are usually engaged in cooperation projects and other forms of support concerning decentralization and were thus a relevant source of information. Consequently, their experience and contacts opened up the access to relevant actors in the field who, in turn, were usually helpful to identify further potential interviewees. This eventually led the way into the regions and enabled us to conduct interviews with local government officials and observer organizations. Based on an evaluation of official organizations, news reports and legal documents, we also searched for additional persons of interest and either tried to find their contact credentials (e.g., LinkedIn, Facebook, email) or asked other contacts for their help to get in touch with them. However, lacking a connection to a colleague or preexisting contact, potential interview partners were sometimes harder to motivate for an interview.

A trip to peripheral regions differs significantly between the countries. In small countries like Jordan, it was most convenient to arrange a driver for one day who would drive from one interview to the other, and then back to the city in the evening. It is also the safest way to travel to the periphery, especially for female researchers. In the region, most of the times we had a contact person who already waited for us on arrival to take us to the interviews. We deliberately decided not to use recording devices in our interviews. Due to the authoritarian (or transitional) research environment we worked in, we tried to minimize risks and vulnerabilities to surveillance (digital and otherwise) for both our contacts and us (Ryan and Tynen 2020). We stored contact information of our interviewees and the 
notes we took separately and encrypted sensitive files. Lack of word-forword-transcripts may result in the loss of some information, but overall it was more compatible with the dynamic interview settings we found ourselves in: Depending on the interviewee, sensitive questions had to be asked with caution, if at all. Some were eager to provide information, others rather hesitant, especially when asked for names, informal practices, and financial flows. Recording the interviews can thus further irritate interview partners and may prompt them to withhold important information. In addition, many interviews took place in noisy surroundings like coffee shops, restaurants or hotel lobbies, sometimes we changed locations in the middle of an interview as our contacts wanted to show us something. At times, interviews evolved into group interviews when our contacts introduced us to colleagues and partners.

Most of our interviews were conducted in French and English. For some interviews, especially those outside the city centers, we arranged a professional interpreter or a colleague who is fluent in the local Arabic dialect. Our interviews were semi-structured encounters based on an open questionnaire that we prepared in coordination with the research team. However, we stayed open-minded and adapted the questions with respect to the position or background of each interview partner. We frequently incorporated important news or questions raised by prior interviewees into our set of questions to permanently advance our understanding of the issues. During an interview, it is rarely possible 4 to ask each question prepared for the questionnaire. Often interview partners raise their own points or open up a new perspective, which may eventually change the structure of the interview. Flexibility is thus extremely important to accommodate the different insights and backgrounds of our partners as well as the different lengths of the interviews (from 30 minutes shared between interviewee, translator and interviewer to three hours one-on-one).

\section{Public finance and subnational data: Issues of quality and availability}

While elite relations are vital for our understanding of decentralization under neopatrimonialism, the fiscal relations of center and periphery are another important tool to assess the state of decentralization in the MENA region. Reliable and long-term data on public finance are very scarce in the

4 It would also not have been sensible to do so. Not every contact is in the position to inform in detail on all three topics of our interview structure. 
region and the situation is even worse for subnational finance. Consequently, most quantitative studies on the workings and effects of (fiscal) decentralization exclude the Arab world from their analyses. ${ }^{5}$

Even when we focus on macro level data independent of decentralization, the MENA region lags behind other world regions in data accessibility and quality. It is the only region that saw a decline in its statistical capacity (i.e. data quality and accessibility) between 2005 and 2018. Its mean is now last among world regions behind Sub-Sahara Africa (see Figure 2). Even where the World Bank registers relatively high levels of statistical capacity, we still face a lack of micro level data (Arezki et al. 2020). Definitions and accumulations of core state statistics might deviate from overarching World Bank definitions and thus vary between cases.

Figure 2: Development and statistical capacity of world regions in 2018

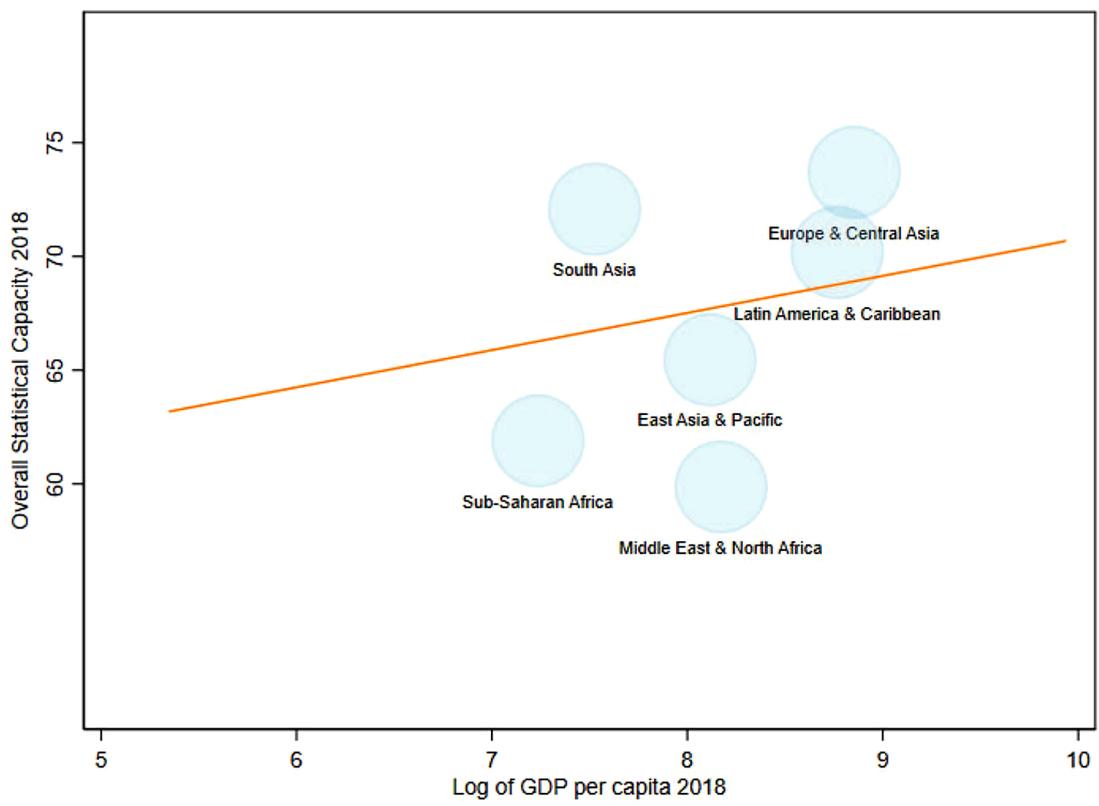

Arezki et al. (2020, 17).

5 Ivanyna and Shah (2014) are an exception among large-n studies on decentralization in this regard. 
The problem seems accentuated when working with data on subnational phenomena. Data on subnational finance was often inaccessible for parts of our period of investigation (Jordan, Tunisia). Our analysis sometimes suffers from a palpable lack of disaggregated data (Egypt, Morocco), missing data from parts of the reporting subnational entities (Jordan, Tunisia) or reported values that vary between different official ministry sources (Tunisia, Jordan).

Figure 3: Statistical capacity score for MENA countries, 2018

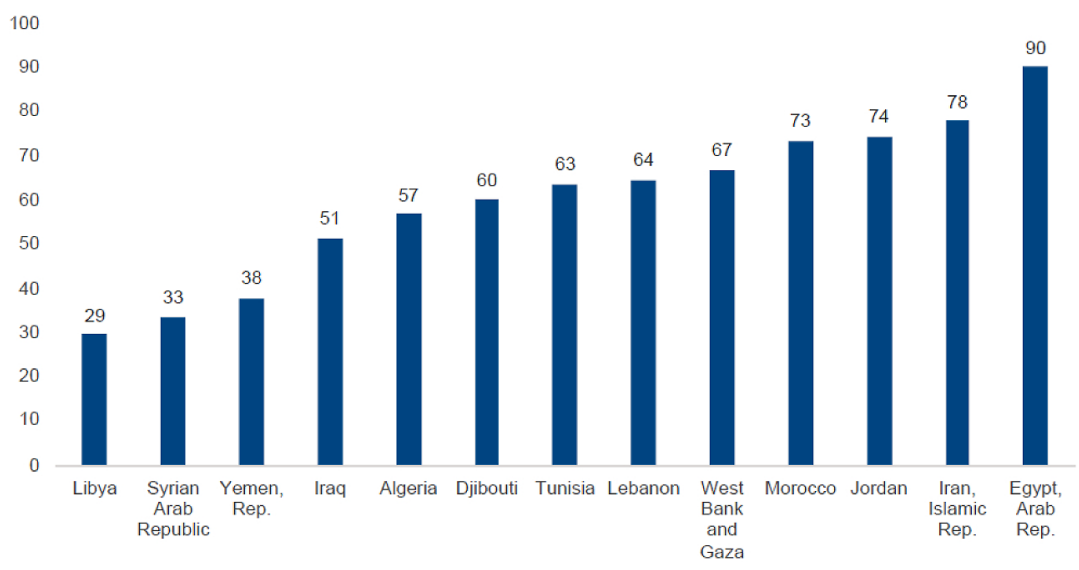

Arezki et al. $(2020,18)$.

World Bank data suggest the highest statistical capacity for Egypt (see Figure 3). This high value, however, does not translate into an easier access to subnational data for our purposes of investigation - on the contrary. The Egyptian regime faces allegations it would hide its vast military spending through artificially downsizing military resources in state statistics. Many comparative social science datasets have not updated their latest ratings on Egypt because access to the field and other sources of information have become ever more difficult to acquire.

Kandil (2020) claims that the shortfalls in the quality and accessibility of official data in MENA countries cannot solely be explained by insufficient resources or new procedures: "National statistics centres in most MENA countries were set up decades ago, so they have had enough time to build capacity; the dearth of adequate, accurate, reliable and timely data has to be explained by unwillingness to share information." (Kandil 2020) 
In this region as in other world regions, the possibilities and incentives for governments to manipulate reported data, e.g. in times of crises to guarantee stability, are seldomly discussed but often presupposed problems of political economic analyses (Aragão and Linsi 2020; Wallace 2014). The problem is not unique to autocratic regimes, but likely more accentuated in some, as for example data problems in Egypt suggest.

We acknowledge these limits and accept that an analysis of subnational fiscal data in the MENA region may inevitably show gaps at times. Nevertheless, even with fragmented data it is possible to reveal certain trends over time. We are also aware that official fiscal data may not always document the de facto numbers, especially not under the condition of neopatrimonialism. Interviews with subnational government officials, civil society organizations and country experts can make up for this by helping to detect possible inconsistencies in fiscal flows and the politics behind the presentation of data. In our analysis, whenever possible, we combine quantitative data on fiscal decentralization and local finance with qualitative material from original field research and secondary literature to shed light on the dynamics of fiscal decentralization in the MENA.

\section{References}

Aragão, Roberto, and Lukas Linsi. 2020. "Many Shades of Wrong: What Governments do when they Manipulate Statistics." Review of International Political Economy: 1-26. doi: 10.1080/09692290.2020.1769704.

Arezki, Rabah, Daniel Lederman, Amani Abou Harb, Nelly El-Mallakh, Rachel Yuting Fan, Asif Islam, Ha Nguyen, and Marwane Zouaidi. 2020. How Transparency Can Help the Middle East and North Africa. Middle East and North Africa Economic Update (April). Washington, D.C.: Worldbank.

BTI. 2020. "Bertelsmann Transformation Index. Atlas." Accessed January 29, 2021. https://atlas.bti-project.org/.

Cochrane, Allan. 1998. "Illusions of Power: Interviewing Local Elites.” Environment and Planning A: Economy and Space 30 (12): 2121-2132. doi: 10.1068/a302121.

Glasius, Marlies, Meta de Lange, Jos Bartman, Emanuela Dalmasso, Aofei Lv, Adele Del Sordi, Marcus Michaelsen, and Kris Ruijgrok. 2018. Research, Ethics and Risk in the Authoritarian Field. Cham: Palgrave Macmillan.

Grimm, Jannis, Kevin Koehler, Ellen M. Lust, Ilyas Saliba, and Isabell Schierenbeck. 2020. Safer Field Research in the Social Sciences: A Guide to Human and Digital Security in Hostile Environments. London: SAGE. 
Hoffmann, Anja, Malika Bouziane, and Cilja Harders. 2013. "Analyzing Politics Beyond the Center in an Age of Transformation." In Local Politics and Contemporary Transformations in the Arab World. Governance Beyond the Center, edited by Anja Hoffmann, Malika Bouziane, and Cilja Harders, 1-24. Basingstoke: Palgrave Macmillan.

Ivanyna, Maksym, and Anwar Shah. 2014. "How Close Is Your Government to Its People? Worldwide Indicators on Localization and Decentralization.” Economics: The Open-Access, Open-Assessment E-Journal 8 (3): 1-62. doi: http://dx.doi.org/10.5 018/economics-ejournal.ja.2014-3.

Kandil, Magda. 2020. "Why Data Transparency Matters for MENA Economies." The Forum, July 27. Accessed January 29, 2021. https://theforum.erf.org.eg/2020 /07/27/data-transparency-matters-mena-economies/.

Mikecz, Robert. 2012. "Interviewing Elites: Addressing Methodological Issues." Qualitative Inquiry 18 (6): 482-493. doi: 10.1177/1077800412442818.

Morris, Zoë Slote. 2009. “The Truth about Interviewing Elites.” Politics 29 (3): 209217. doi: 10.1111/j.1467-9256.2009.01357.x.

OECD, and UCLG. 2019. 2019 Report of the World Observatory on Subnational Government Finance and Investment - Country Profiles. Paris: OECD.

Perthes, Volker. 2004. "Politics and Elite Change in the Arab World." In Arab Elites: Negotiating the Politics of Change, edited by Volker Perthes, 1-34. Boulder: Lynne Rienner Publishers.

Rice, Gareth. 2010. "Reflections on Interviewing Elites.” Area 42 (1): 70-75. doi: 10.1111/j.1475-4762.2009.00898.x.

Ryan, Caitlin M., and Sarah Tynen. 2020. "Fieldwork Under Surveillance: Rethinking Relations of Trust, Vulnerability, and State Power.” Geographical Review 110 (1-2): 38-51. doi: 10.1111/gere.12360.

Transparency International. 2020a. “Corruption Perceptions Index.” Accessed January 29, 2021. https://www.transparency.org/en/cpi/.

Transparency International. 2020b. “Global Corruption Barometer.” Accessed January 29, 2021. https:/www.transparency.org/en/gcb/.

V-Dem. 2020. "Varieties of Democracy. Variable Graph.” V-Dem Institute. Accessed January 29, 2021. https:/www.v-dem.net/en/analysis/VariableGraph/.

Wallace, Jeremy L. 2014. "Juking the Stats? Authoritarian Information Problems in China." British Journal of Political Science 46 (1): 11-29. doi: 10.1017/ S0007123414000106.

Wessel, Sarah. 2018. "The 'Third Hand' in Egypt. Legitimation and the International Dimension in Political Transformations." Middle East Law and Governance 10 (3): 341-374. doi: 10.1163/18763375-01003006.

Woods, M. 1998. "Rethinking Elites: Networks, Space, and Local Politics." Environment and Planning A: Economy and Space 30 (12): 2101-2119. doi: 10.1068/a302101.

World Bank. 2020. "World Bank Data.” Accessed January 29, 2021. https://data.wor ldbank.org. 
